\title{
The Integration of Color and the Retention of Text
}

\author{
Michelle E. Lucic ${ }^{\mathrm{a}}$, Patricia R Talarczyk ${ }^{\mathrm{a}}$
}

\begin{abstract}
The following essay will present research that studies the interweaving of color and memory. The purpose of this research is to evaluate the effectiveness of different formats of color within a prose fiction text, and to show how color affects the retention of the information read. To perform the study, one passage made in three different formats - black and white throughout the text, colored font on random words, or highlighted text on random words - will be randomly assigned to Advanced Placement (AP) and College Prep (Regular) English class juniors, followed by a test based on accuracy. The results show that color has a more positive influence than normal black and white text in regards to retaining information. Moreover, women overall were seen to perform significantly better on the text with highlighted text compared to colored font, whereas men overall were seen to be more successful using colored font than highlight. One can conclude from this research that using color to study and remember information for a test or a job-related interview can improve one's performance. Due to the positive influence of color, students should ask their teachers to promote a more color-coded study plan, present key parts in a slideshow using highlighting or colored font, or more, which could lead to higher student scores and steer attention towards the information being given.
\end{abstract}

Keywords: Color; Memory; Attention; Text; Students

The developing teenage mind is constantly trying to make connections to the outside world and form quick, coherent conclusions based on what is presented to them and the context a situation is presented in. Researchers have been tackling the topic of the developing minds of humans for years, discovering through experimentation and observation information that has excelled the pace of not only science but social progress as well. With new technology flooding the globe, and all the latest discoveries enhancing the way civilization continues, one comes to question how all of this information can connect into a deeper understanding of smaller details. These smaller details are what could, quite frankly, lead up to a more prepared future for teens, and allow for a short-cut into the adult world when gaining and retaining information out of the average rate. This small detail can be summed up with the following two words: adding color. With an acquisition into the details of how color affects memory, the question of whether certain formats of color in a text will affect the retention of information in Northeast Ohio high school students will be studied. These final results will have a chance of possibly advancing future studying methods to a local/global scale, and lead to effective ways to memorize future career-pertaining information.

\section{Literature Review \\ The basics of memory}

In order to be able to test the effectiveness of manipulating memory through adding color, one needs to learn about the sections of fundamental knowledge behind the experiment. For example, memory is commonly classified as being the mental process of encoding, retaining, and retrieving information (Radvansky, 2006). And, though functions in the brain that relate to memory - such as the hippocampus, which was first described in 1587 by a Venetian anatomist named Julius Caesar Aranzi (Mandal, 2017) - have been discovered, how those different organs and cognitive systems specifically distribute their weight of the memorization process is still being researched amongst scientists to this day. The majority of current debate is centered around the ability to heighten memory and have more elevated retention capabilities; however, those cannot be found without the basic knowledge of memory.

\section{Brief model overviews}

An acclaimed memory model, known as the multi-store model, was discovered by Richard Atkinson and Richard Shiffrin in the late 1960s. In the model, memory is sectioned into three structures: the sensory register or sensory encoder, short-term memory, and long-term memory. In this model environmental stimuli are brought to the sensory register or sensory encoder, which then register the information and briefly retain parts, before a small selection of the retained information is then moved into the short-term memory system. Information from there would then be transitioned into long-term memory for appesempiternal storage and a person would be able to pull out any of the information from their long-term storage at any time (Atkinson and Shiffrin, 1968). For the purpose of this research, the experiment performed will focus on the sensory register and short-term memory aspect of memorization, as this paper will not be able to analyze long-term retention of any form.

Another memorization model was introduced by Fergus Craik and Robert Lockhart, in which "the processes involved in memory were more important than the structures of the memory system," (Dzulkifli and Mustafar, 2013, para. 8) which was a popular opposing view to Atkinson and Shiffrin. The model discusses how these memory processes are thought to be on a supposed continuum: from thin, sensory processes to deep, semantic memory processes. The thinner memory processes simply involved a face-level analysis of details such as physical characteristics. The intermediate memory process involves an extent of recognition or labeling, which leads to deeper retention and a higher level of analysis. And, finally, the information gained will accumulate in the long-term memory store as a result of the bulk of the interpretation and evaluation done on the environmental 
input around the person (Dzulkifli and Mustafar, 2013). This aspect of memorization will also be found to be used by the participants throughout the experiment.

\section{The connection}

More theories erupted after the grounding of these two models. As more models came to light, multiple questions began to spark ideas of ways to improve memory and color slowly crept its way into the topic. Beginning back in 1976, Frank Farley and Alfred Grant oversaw experiments measuring the influence of color and discovered colored multimedia presentations were more effective in improving attention and enhancing memory performance (Farley and Grant, 1976). More experiments investigating the influence of color on the human cognitive processes were conducted since then, like the study performed by Maria Olkkonen and Sarah R. Allred on how color perception affects short-term memory. The illation of their study was the argument that shortterm memory affects color processing in a way that is similar to a subject taking in prior information in fluctuating levels which depend on the variability in the sensory signal (Olkkonen and Allred, 2014). The study suggests an abutting connection between perceptual functions and the way memory processes with color, which is the backbone of researching more into the realm of color and memory.

\section{The importance of color}

Color has been presumed to be one of the most essential visual experiences for human beings since the beginning of research on the field (Adams and Osgood, 1973). Due to color functioning as an essential information channel to the human cognitive system, color has been able to play a noteworthy role in improving memory performance on numerous tasks involving both athletic and non-athletic activities (Wichmann, Sharpe, and Gegenfurtner, 2002). Surface color has also been seen to have an enlightening indication of many notable characteristics, such as the edibility of certain foods (Olkkonen and Allred, 2014). With these key facts in mind, one can question the thought of how certain colors possibly assert dominance over other colors in the human mind, and how that dominance could affect the memory of someone after an experience with the dominant color. This question brings light to the idea of connecting capturing a certain color to capturing someone's attention.

\section{The Attention Factor}

Attention has been referred to frequently as "the cognitive process of selecting information that is available in the environment" (Dzulkifli and Mustafar, 2013, para. 10). Attention will vary and periodically focus on a certain amount of information that is processed in our mind (Dzulkifli and Mustafar, 2013), and the attention connected to specific stimuli will increase the probability memory storage (Burke, Heuer, and Reisberg, 1992). In other words, the more attention one gives to certain information, the more likely one is to remember it. A copious amount of studies have supported the argument that attention increases the degree of memorization in terms of the recall rates (Smilek, Dixon, Cudahy, and Merikle, 2002), as well as a more swift reaction time (MacKay and Ahmetzanov, 2005). Understanding this, the color that is seen to bring the most attention will be the color studied in this experiment.

As previously stated, how color affects someone's attention and memory has been an important area of study in the field of psychology. However, despite ambiguous disputes within the broad topic of attention, memory, and color over the years (Madden, Hewett, and Roth, 2000), there have been general consensuses in regard to its effects. Primarily, the fact that color generally holds more attention than black and white (Schaie and Heiss, 1964), and that warm colors such as red will provoke more neural arousal than cool colors such as blue will (Birren, 1978) has been agreed to. These specific statements, discriminating between color and attention lead to a discussion on the issue of gaps in the research.

\section{The gap in the research}

A gap that has been clearly noticed is that there are a plethora of studies covering how color affects attention with visual objects and separated words - not in a text-based format -, but no real study connecting color to memorizing a passage or piece of text could be seen. There was the study by well-known psychologist John Ridley Stroop, which showed a slight connection of the Stroop Effect (MacLeod, 1991 p. 163-165), but even this was not a clear connection to the research. The Stroop Effect is essentially a list of words that are colors, but each word has a font color that does not correlate with the word. For the Stroop experiment, the subject has to say the color of the word instead of the word itself (e.g. trying to say the font of the word, which is red, instead of the actual text, which says blue). Though it does contain words instead of visual cues or other, it does not address the comprehension and test-based style which will be achieved through this study. Nevertheless, Stroop's study will be the beginning of the bridging of a gap for the experimental process.

When looking at the educational perspective, it is visible that a there has been an increased push on academic achievement. Understanding such, it is important to note that students must learn to utilize their cognitive abilities to the fullest, as it may contribute higher academic achievement (Mariam and Intan, 2012). With that in mind, it is important to note that the stimuli available in the environment have to have the ability to cultivate attention and memory in order for a stimulus to be better remembered. Not only have researchers shown evidence that color is a variable that has this potential, researchers have also addressed that colors can influence the level of attention in an individual, as well as give rise to an emotional arousal which aides in processes later enhancing memory performance (Farley and Grant, 1976). Keeping such in mind, the question of the effectiveness of color on key information in a passage will now be examined, with the hypothesis being color positively affects the subject's retention of information. 


\section{Method \\ The base of the research}

The type of method used for this study of the relationship between memory and color was the experimental method, due to the need to form results instead of compare previous results. In order to conduct the experiment in a way that made students feel familiar with the study, the study was molded to mimic a comprehension exam. Throughout the experiment, nominal data questions such as whether or not a piece of text was in a passage, whether or not the subject remembers where a topic was discussed in a passage, what their birth sex is (to see if there are differences between a man's brain and a woman's brain in regards to this research), and more would be used. The results were processed with a quantitative data collection, which would be based on comparing the accuracy of the participant answers. The accuracy of the five multiple choice answers was based on a point system scale and would be recorded as percentage correct. Answers were then compared between other results based on different sections and divisions of people (eg. comparing different genders, ages, etc.).

Additionally, the data analysis will be based on a quantitative, interval approach. The specific type of statistical analysis used would be an ANOVA table, due to the fact that the study compares independent group means comprised of ratio/interval data. Subjects in the study were 2017-2018 juniors in a local Northeast Ohio high school, which were currently taking either Advanced Placement (AP) Language and Composition or a College Prep (Regular) English 11 class at a local school. Subjects of the experiment will range from 16 to 17 years old and would be a mix of both males and females. All resources provided to participants and taken from participants would be on paper instead of on an online form, and all results remained anonymous before, during, and after the study. The subject's participation was voluntary. No one was paid for reading the passage or taking the exam.

\section{Preliminary work}

The study involved students reading a passage and answering questions in a test-formatted packet. For the purposes of the experiment, a previously constructed passage was used instead of a passage made by the examiner. The essay used in the experiment was a passage adapted by the ACT board from the short story American History by Judith Ortiz-Cofer ("The Official ACT," 2017 p. 270). The survey passed out to the participants for the study was a nine-question test, following a five-question demographic questionnaire. The survey included only nominal questions and identifications, which targeted personal characteristics and factors such as birth sex, gender, color-blindness, and age, as well as a participant's ability to bullet point characteristics of the passage, summarize its story, and answer multiple-choice questions pertaining to the contents of the text. The answers to these questions, when analyzed, will reveal the participant's level of retention of the information, as well as if there are certain demographics that differentiate data dramatically (eg. men performing better than women when color is added).

\section{Sampling procedures and experimental measures}

Selecting participants for the experiment can be defined as random and voluntary. The only non-random sampling that occurred would be the fact that the population consisted of 11th-grade juniors in an AP or Regular English class. Passages were given to the participants randomly in the following repeating order: black and white, colored font, highlight. All participants were given the same instructions and were encouraged to be honest during the exam. In this experiment, the variable that was being measured was the extent of which a student could successfully retain information from the text of a prose fiction ACT passage after reading the text once within however much time deemed necessary by the student.

\section{The process of the experiment}

The first part of the process was to email English Language teachers and request permission to perform the study. Of the two teachers asked, both consented. The experiment required two Regular English classes and two AP English classes. Of each class, at least 25 people must be in attendance (the actual class should range from 25 to 27 students). From there, consent of the participants must be gained through a form signed by the student. After a reminder that participation is voluntary, the experiment began. Of the people who were asked, all consented to perform the experiment, and no seen complications with their performance arose.

When addressing the subjects a script was read, which contained the purpose of the project, what is expected of them throughout the project, etc. Once the script is finished each class is expected to read a passage which will either be black and white, have colored font, or have highlighted text. After participants are finished reading over the text once, they are expected to set the passage face-down on the table and start the exam, which should be answered accurately, but at the same time honestly. There would be an "I do not know" option on every multiple choice question asked, and if a participant really could not remember they are encouraged to select that choice instead of guessing. After the survey participants were required to fill out a demographic survey sheet and pass the assessments over to the examiner.

\section{The details behind the decisions}

Participants were specifically chosen to be eleventh grade English classes because taking an ACT-style passage and answering the test afterward would provide a form of additional aid for their ACT practice, as well as keep the class on track with its lessons due to the assessment resembling a reading comprehension test.

The passage used contained a switch in the school name. The change was made due to a practice participant not knowing that the original school name was, in fact, a school name. The ACT passage used in the experiment was chosen because it has been pre-verified to be tested with, and was a prose fiction passage from 1992. The prose fiction theme made sure no participant would have prior knowledge about the passage or know more than another participant about the topic being discussed. 
There were eight text-related questions, with three being in color within the text and five not being in color. The blend of colored and uncolored questions was to keep the data as unbiased as possible and to see if the colored passages would make participants only be able to answer the colored test questions correctly.

The color red was chosen to be the color in the passage because, as stated previously, warmer colors tend to arouse more attention than cooler colors (Birren, 1984). By increasing their attention on a certain part of the text, the question of, "Would the students remember the information better?" and "Would they remember non-colored information?" could be answered. And, seeing as work and testing would be computed, one could run the results through thorough analysis.

\section{Results and Analysis}

The questions scored within Tables 1, 2, 3, and 4 are the multiple choice questions within the survey given to the students. Extended response questions were not scored within the first four tables due to too much variation of data with the responses, and possible confusion when assessing student grade averages. Tests were not graded or scored in the results section if the participant had circled "no" for the question asking if the reader understood the text, if a student was caught cheating during the assessment, or if a student was seen not taking the exam seriously (eg. taking three minutes to read the passage and writing "I don't know" next to each question).

Table 1. Total average accuracies on multiple choice scores for all three formats

\begin{tabular}{|lccc|}
\hline Format & AP Score & Reg Score & Combined Score \\
\hline Black and White Text & $51 \%$ & $46 \%$ & $49 \%$ \\
\hline Colored Font Text & $53 \%$ & $58 \%$ & $56 \%$ \\
\hline Highlighted Text & $59 \%$ & $57 \%$ & $58 \%$ \\
\hline
\end{tabular}

A summary of the answers examined from the study of black and white can be seen down below in Table 2. Students who had taken the black and white version of the test had done worse in all of the versions of the test with the scores of AP, Regular, and their combined scores being $51 \%, 46 \%$, and $49 \%$ respectively (refer to Table 1 ). Table 2 's section of students were also seen to have the most fluctuating percentages in their accuracy with each question, ranging from $27 \%$ students knowing the correct answer to $71 \%$ of the students knowing the correct answer. Within this version of the test, the students who were 17 years old scored higher than 16-year-old students by at least $10 \%$ in both the AP and Regular English classes. In regards to gender, the division remained from $30 \%$ to $56 \%$. AP women scored the highest, with a $56 \%$ overall score (scoring $16 \%$ higher than AP men, $7 \%$ higher than Regular men, $26 \%$ higher than regular women).

Table 2. Results of the study of student answers with black and white text only

\begin{tabular}{|lccccccccc|}
\hline Student & Q.2 & Q.4 & Q.5 & Q.6 & Q.8 & $\begin{array}{c}\text { Female } \\
\text { Average }\end{array}$ & $\begin{array}{c}\text { Male } \\
\text { Average }\end{array}$ & $\begin{array}{c}\text { 17 years old } \\
\text { Av erage }\end{array}$ & $\begin{array}{c}\text { 16 years old } \\
\text { Av erage }\end{array}$ \\
\hline AP Correct & $50 \%$ & $71 \%$ & $43 \%$ & $29 \%$ & $57 \%$ & $56 \%$ & $40 \%$ & $60 \%$ & $47 \%$ \\
\hline AP Incorrect & $50 \%$ & $29 \%$ & $57 \%$ & $71 \%$ & $43 \%$ & $44 \%$ & $60 \%$ & $40 \%$ & $53 \%$ \\
\hline Reg Correct & $27 \%$ & $64 \%$ & $45 \%$ & $27 \%$ & $64 \%$ & $30 \%$ & $49 \%$ & $53 \%$ & $43 \%$ \\
\hline Reg Incorrect & $73 \%$ & $36 \%$ & $55 \%$ & $73 \%$ & $36 \%$ & $70 \%$ & $51 \%$ & $47 \%$ & $57 \%$ \\
\hline
\end{tabular}

Answers resulting from the study of colored font can be seen down below in Table 3. This portion of students had done better than the black-and-white students by 7\%, with the AP, Regular, and combines scores earning 53\%, 58\%, 56\% respectively (refer to Table 1). Though this group had the highest accuracy in regards to specific questions, the group had averaged into a lower score due to the $33 \%$ and $25 \%$ accuracy ratings that the Regular students had responded. For this specific test 16-year-old students had scored higher than 17-year-old students for both the AP and Regular classes. Moreover, the break-up in scoring showed men had either retained or understood the information better with the colored font. AP men taking the exam had the most substantial advantage with colored font, scoring 18\% higher than AP women, 20\% higher than Regular women, and only 5\% higher than Regular men. Though women had seen a decrease in their accuracy compared to the black-and-white scores, they still remained around a 50\% estimate.

Table 3. Results of the study of student answers with colored font 


\begin{tabular}{|lccccccccc|}
\hline Student & Q.2 & Q.4 & Q.5 & Q.6 & Q.8 & $\begin{array}{c}\text { Female } \\
\text { Average }\end{array}$ & $\begin{array}{c}\text { Male } \\
\text { Average }\end{array}$ & $\begin{array}{c}\text { 17 years old } \\
\text { Average }\end{array}$ & $\begin{array}{c}\text { 16 years old } \\
\text { Average }\end{array}$ \\
\hline AP Correct & $33 \%$ & $83 \%$ & $50 \%$ & $67 \%$ & $42 \%$ & $49 \%$ & $67 \%$ & $48 \%$ & $57 \%$ \\
\hline AP Incorrect & $67 \%$ & $17 \%$ & $50 \%$ & $33 \%$ & $58 \%$ & $51 \%$ & $33 \%$ & $52 \%$ & $43 \%$ \\
\hline Reg Correct & $33 \%$ & $83 \%$ & $75 \%$ & $25 \%$ & $75 \%$ & $47 \%$ & $62 \%$ & $52 \%$ & $63 \%$ \\
\hline Reg Incorrect & $67 \%$ & $17 \%$ & $25 \%$ & $75 \%$ & $25 \%$ & $53 \%$ & $38 \%$ & $48 \%$ & $47 \%$ \\
\hline
\end{tabular}

Answers resulting from the study of highlighted words can be seen down below in Table 4. The data of the answers shows that this group was the most stable group in terms of the most stable accuracy range. They were also fairly consistent in terms of their overall scores, with AP, Regular, and combined sores earning 59\%, 57\%, and 58\% respectively (Table 1). As can be seen throughout all four data tables, the highlighted version of the test remained the most accurate group, and both genders were seen to have more elevated scores than the black-and-white tests. AP women's scores had skyrocketed in this section, earning a score of $78 \%$, which is $16 \%$ more than Regular women, $15 \%$ more than Regular men, and $31 \%$ more than AP men. Though the unusual $31 \%$ gap between AP men and women has been presented, both scorings still remain higher than the black-and-white control group.

Table 4. Results of the study of student answers with highlighted words

\begin{tabular}{|lccccccccc|}
\hline Student & Q.2 & Q.4 & Q.5 & Q.6 & Q.8 & $\begin{array}{c}\text { Female } \\
\text { Average }\end{array}$ & $\begin{array}{c}\text { Male } \\
\text { Average }\end{array}$ & $\begin{array}{c}\text { 17 years old } \\
\text { Av erage }\end{array}$ & $\begin{array}{c}\text { 16 years old } \\
\text { Average }\end{array}$ \\
\hline AP Correct & $41 \%$ & $71 \%$ & $76 \%$ & $41 \%$ & $59 \%$ & $78 \%$ & $47 \%$ & $53 \%$ & $62 \%$ \\
\hline AP Incorrect & $59 \%$ & $29 \%$ & $24 \%$ & $59 \%$ & $41 \%$ & $22 \%$ & $53 \%$ & $47 \%$ & $38 \%$ \\
\hline Reg Correct & $47 \%$ & $67 \%$ & $73 \%$ & $33 \%$ & $73 \%$ & $62 \%$ & $63 \%$ & $63 \%$ & $54 \%$ \\
\hline Reg Incorrect & $53 \%$ & $33 \%$ & $27 \%$ & $67 \%$ & $27 \%$ & $38 \%$ & $37 \%$ & $37 \%$ & $46 \%$ \\
\hline
\end{tabular}

Therefore, one can note from the results presented that color does positively impact a student's ability to retain information from a passage provided to them. Overall, the results are seen to be fairly consistent with the hypothesis that color positively affects a person's ability to remember information. Though there were unexpected findings with certain ages performing better in certain formats, and an outlier for the AP males' scoring in the highlighted text section, an averaging of the entire text (including the extended response sections) through ANOVA showed that the results were statistically significant.

In order to eliminate human error while calculating significance, an online ANOVA and significance calculator ("One-Way ANOVA Calculator," n.d.) was used. Tables 5 and 6 illustrate the overview of the statistical analysis of the data. By taking away the tests in which students had stated they had not understood the passage, grading the entirety of the test instead of just the multiple choice, and sectioning each of the papers by format type instead of class, the f-ratio value was found to be set at 3.20338 , and the p-value was found to be at .046397 . This calculation shows that the result of this analysis is significant at approximately $\mathrm{p}<.05$, which verifies the experiment as being statistically significant.

Table 5. Summary analysis using the grades including both multiple choice and short answer

\begin{tabular}{|lcccc|}
\hline Treatments & BW & F & H & Total \\
\hline $\mathbf{N}$ & 23 & 24 & 29 & 76 \\
\hline $\boldsymbol{\Sigma} \mathbf{X}$ & 12.4 & 14.7 & 19.9 & 47 \\
\hline Mean & 0.5391 & 0.6125 & 0.6862 & 0.6184 \\
\hline $\boldsymbol{\Sigma} \mathbf{X} \mathbf{2}$ & 7.96 & 9.85 & 14.71 & 32.52 \\
\hline Std.Dex. & 0.2407 & 0.1918 & 0.1941 & 0.2146 \\
\hline
\end{tabular}

Note. All results have been verified

$* B W=$ black-and-white text $* F=$ colored font text

$* H=$ highlighted text 
In regards to the black-and-white test scores (Table 2), a fluctuation in the results could have been due to the students' inability to focus on the information given to them when trying to retain information. The sudden accuracy in answering questions for both the colored font (Table 3) and the highlight (Table 4) test takers could be due to the fact that the phrases or words changed in their passages could have sparked the right answers to the questions asked. Answers also could have been more accurate due to some answers to the questions being presented in the text with colored font or highlight, or by those questions being next to the formatted text. Highlighting might have been a more effective tool than colored font due to highlighting already being the normal use of pointing out key information, which would emphasize the information while being less distracting than the font.

Table 6. The calculation of result details and significance

\begin{tabular}{|c|c|c|c|}
\hline Source & SS & df & MS \\
\hline Betw een-treatments & 0.2787 & 2 & 0.1393 \\
\hline Within-treatments & 3.1755 & 73 & 0.0435 \\
\hline Total & 3.4542 & 75 & $F=3.20338$ \\
\hline
\end{tabular}

\section{Conclusion}

Though the improvement in performance due to color was expected, many unexpected results were presented within the exams as well. For example, one peculiarity within the study was that there was a noticeable difference between genders in regards to how the format affected a participant's retention. Since there was a noticeable gap, a future study due to this discovery could be the answering of why there is a difference between genders in the retention of colored information - whether that study is through social, neurological, or psychological research. The realization of color possibly affecting those who are colorblind could also lead to a study of how a change in color affects certain students, which could improve the advancement of student aid in retention. A question of whether or not color groups had been more distracted while performing the experiment could lead to a 'distractor' study, in which the attention of a student is measured instead of the information retained by only highlighting words and phrases not asked about in a test. This experiment was only the tip of the iceberg in regard to the uncovering of an entire gap of areas not yet questioned, which is why this area of research needs to be considered on a greater scale than it has in previous years.

Directions for future studies are seen to be available, but limitations within this experiment could also lead to a renewal of this study. A limitation of this color-effectivity study could have been the fact that this study did not reach a broad enough sample space. Juniors were selected due to their more frequent need to perform comprehension tests (eg. ACT exams, SAT exams, English classes, etc.). However, by adding freshman, sophomore, and senior classes into this research, a more stable outcome could have been seen due to an increase in population size. The variety of experience with comprehension tests could have possibly led to a different outcome as well and would have given a more solid answer in regards to the true effectiveness of color. Another setback to the results recorded in this study could have been the fact that people skipped through the exam and did not truly try their hardest, in order to finish early and converse with friends. This could explain the unusual drop in percentage the AP boys had for the highlighted text compared to the other groups who had the same text. Possible issues with colorblindness could have also arisen; however, within this experiment, there was only one student who was colorblind, and the student was randomly assigned to the black-and-white test group. A major component of the study was also to only read the text once and then to turn it around, but due to the proctor not really knowing if the students actually read the passage once before turning it over, students reading the passage more than once could lead to a skewing of results. Considering the status of the experiment being statistically significant, one can assume such limitations did not arise repeatedly enough to disrupt the experiment. Nevertheless, one experiment is not enough to fully grasp the gravity of the way a person's memory model is manipulated through color.

In brief, one can conclude with 95\% confidence ("One-Way ANOVA Calculator," n.d.) from the given results that adding color into a passage is an effective tool for a more successful retention of information in high school students. The implications for this discovery should be publicly known, as this study could lead to more studies searching for a more advanced way of increasing student memory. Due to the positive influence of color, students should ask their teachers to promote a more colorcoded study plan, to present key parts in a slideshow using highlighting or colored font, or to read out of textbooks which have more variation in the way key information is presented on the paper (eg. the vocabulary words are bolded or colored, while main ideas are highlighted). Through this form of studying, higher scores for students could surface, and more students would steer their attention towards the information being given.

\section{References}

Adams, F. M., and Osgood, C. E. (1973). A cross-cultural study of the affective meanings of color. Journal of Cross-Cultural Psychology, 4(2), 135-156. https://doi.org/10.1177/ 002202217300400201 
Atkinson, R. C., and Shiffrin, R. M. (1968). Human memory:

A proposal system and its control processes. In K.W.S.A.J.T. Spence (Ed.), The psychology of learning and motivation (Vol.8). London: Academic Press.

Birren, F. (1984). Color and human response: Aspects of light

and color bearing on the reactions of living things and the welfare of human beings. John Wiley and Sons.

Burke, A., Heuer, F., and Reisberg, D. (1992). Remembering emotional events. Memory and cognition, 20(3), 277-290. Retrieved from https://www.ncbi.nlm.nih.gov/pubmed/150 8053

Dzulkifli, M. A., and Mustafar, M. F. (2013, March). The influence of colour on memory performance: A review. Retrieved from https://www.ncbi.nlm.nih.gov/pmc/articles /PMC3743993/\#b19-mjms-20-2-003

Farley, F. H., and Grant, A. P. (1976). Arousal and cognition:

Memory for color versus black and white multimedia presentation. The Journal of Psychology, 94(1), 147-150 https://doi.org/10.1080/00223980.1976.9921410

MacKay, D. G., and Ahmetzanov, M. V. (2005). Emotion, memory, and attention in the taboo Stroop paradigm. Psychological Science, 16(1), 25-32. https://doi.org/10.1111/j.0956-7976.2005.00776.x

MacLeod, C. M. (1991). Half a century of research on the Stroop effect: An integrative review. Psychological Bulletin, 109(2), 163-203. Retrieved from http://pubman.mpdl.mpg.de/pubman/item/escidoc:2355497/component/escidoc:2355496/MacLeod_1991_Half.pdf

Madden, T. J., Hewett, K., and Roth, M. S. (2000). Managing images in different cultures: A cross-national study of color meanings and preferences. Journal of International Marketing, 8(4), 90-107. https://doi.org/10.1509/jimk.8.4.90.19795

Mandal, M. D. (2017, August 03). What is the hippocampus? Retrieved from https://www.news-edical.net/health/HippocampusWhat-is-the-Hippocampus.aspx

The official ACT prep guide: The only official prep guide from the makers of the ACT (2018 ed.). (2017). Hoboken, NJ: John Wiley and Sons.

Olkkonen, M., and Allred, S. R. (2014). Short-term memory affects color perception in context. PLoS ONE, 9(1), e86488. http://doi.org/10.1371/journal.pone.0086488

Radvansky, G. (2006). Human memory. Boston, MA: Pearson Education Group, Inc.

Schaie, K. W., and Heiss, R. (1964). Color and personality: A manual for the color pyramid test (Farbpyramiden-Test). Huber.

Smilek, D., Dixon, M. J., Cudahy, C., and Merikle, P. M.(2002). Synesthetic color experiences influence memory. Psychological Science, 13(6), 548-552. http://dx.doi.org/10.1111/1467-9280.00496 Social Science Statistics. (n.d.). Retrieved from http://www.socscistatistics.com/Default.aspx

Wichmann, F. A., Sharpe, L. T., and Gegenfurtner, K. R. (2002). The contributions of color to recognition memory for natural scenes. Journal of Experimental Psychology: Learning, Memory, and Cognition, 28(3), 509-520. http://dx.doi.org/10.1037/0278-7393.28.3.509 